\title{
Entre riscos e rabiscos: a percepção da fronteira nos desenhos dos professores de Geografia de Marechal Cândido Rondon/PR
}

\author{
Entre riesgos y garabatos: la percepción de la frontera en los dibujos de \\ los profesores de Geografía de Marechal Cândido Rondon/PR \\ Between scribbles and scrawls: the perception of the border in the \\ drawings of Geography teachers from Marechal Cândido Rondon/PR
}

\author{
Vanderson Rafael Muller Dapper ${ }^{1}$ \\ Jéssica Aparecida de Ávila Follmann² \\ Me. Eliete Woitowicz ${ }^{3}$
}

Dra. Marli Terezinha Szumilo Schlosser ${ }^{4}$

\begin{abstract}
Resumo
Este trabalho apresenta os resultados parciais do projeto de Iniciação Científica Voluntária intitulado: “A percepção da fronteira dos docentes e discentes em colégios públicos de Marechal Cândido Rondon - PR (2016/2017)", vinculado ao Laboratório de Ensino de Geografia (LEG) e Grupo de Pesquisa Ensino e Práticas de Geografia (ENGEO) da Universidade Estadual do Oeste do Paraná (UNIOESTE). Pretende-se discutir a forma como os professores de Geografia do Colégio Estadual Antônio Maximiliano Ceretta, Colégio Estadual do Campo Nilso Franceski e Escola Estadual do Campo Porto Mendes de Marechal Cândido Rondon - PR representam a fronteira em desenho. Os professores expressaram, além do conceito, as concepções que possuem e agregam ao espaço que estão inseridos: a fronteira internacional entre Brasil e Paraguai. Acredita-se que essas percepções influenciam na construção do conceito de fronteira dos alunos em sala de aula. Para realização do trabalho, utilizou-se os questionários abertos respondidos por cinco professores de Geografia dos estabelecimentos de ensino participantes da pesquisa. Eles representaram a fronteira em desenho, responderam o que sentiram ao desenhar e o significado da sua representação. Contudo, os professores desenharam a fronteira como limite entre duas realidades distintas, agregando sentidos e significados do seu cotidiano.
\end{abstract}

Palavras-Chave: Desenhos; Ensino de Geografia; Fronteira; Percepção; Professores de Geografia.

\footnotetext{
${ }^{1}$ Acadêmico do Curso de Licenciatura em Geografia; Universidade Estadual do Oeste do Paraná - UNIOESTE; Marechal Cândido Rondon, Paraná, Brasil; vandersondapper@hotmail.com. Trabalho apresentado no I Seminário Latino-Americano de Estudos em Cultura - SEMLACult, Foz do Iguaçu/PR, Brasil, 2017.

${ }^{2}$ Licenciada em Geografia; Universidade Estadual do Oeste do Paraná - UNIOESTE; Marechal Cândido Rondon, Paraná, Brasil; jessyca_deavila@ hotmail.com.

${ }^{3}$ Mestre em Geografia; Universidade Estadual do Oeste do Paraná - UNIOESTE; Francisco Beltrão, Paraná, Brasil; eliete_wgeo@hotmail.com.

${ }^{4}$ Doutora em Geografia; Universidade Estadual do Oeste do Paraná - UNIOESTE; Marechal Cândido Rondon e Francisco Beltrão, Paraná, Brasil; marlisch20@hotmail.com.
} 


\begin{abstract}
Resumen
Este trabajo presenta los resultados parciales del proyecto de Iniciación Científica Voluntaria titulado: "La percepción de la frontera de los docentes y discentes en colégios púbicos de Marechal Cândido Rondon/PR (2016/2017)', vinculado al Laboratorio de Enseñanza de Geografía (LEG) y al Grupo de Pesquisa Enseño y Prácticas de Geografía (ENGEO) de la Universidad Estadual del Oeste de Paraná (UNIOESTE). Se pretende discutir la forma en que los profesores de Geografía del Colegio Estadual Antônio Maximiliano Ceretta, Colegio Estadual del Campo Nilso Franceski y Escuela Estadual del Campo Porto Mendes de Marechal Cândido Rondon-PR representan la frontera en dibujo. Los profesores expresaron además del concepto, las concepciones que tienen y agregan al espacio que están insertados: la frontera internacional entre Brasil y Paraguay. Se cree que estas percepciones influencian en la construcción del concepto de frontera de los alumnos en la clase. Para la realización del trabajo, fue utilizado los cuestionários abiertos respondidos por cinco profesores de Geografía de los establecimientos de enseñanza participantes de la pesquisa. Ellos representaron la frontera en dibujo, respondieron lo que sintieron al dibujar y el significado de su representación. Pero los profesores dibujaron la frontera como límite entre dos realidades distintas, agregando sentidos y significados de su cotidiano.
\end{abstract}

Palabras claves: Dibujos, Enseñanza de Geografía; Frontera; Percepción; Profesores de Geografía.

\begin{abstract}
This paper presents the partial results of the Voluntary Scientific Initiation project entitled: "The perception of the border of teachers and students in public schools from Marechal Cândido Rondon - PR (2016/2017)", linked to Geography Teaching Laboratory (LEG) and Geography Teaching and Practices Research Group (ENGEO) of the Universidade Estadual do Oeste do Paraná (UNIOESTE). The objective is to discuss how Geography teachers of the Colégio Estadual Antônio Maximiliano Ceretta, Colégio Estadual do Campo Nilso Franceski and Escola Estadual do Campo Porto Mendes from Marechal Cândido Rondon - PR represent a border in drawing. The teachers expressed, beyond the concept, how concepts that they have and aggregate to the space they are inserted: an international border between Brazil and Paraguay. It is believed that these perceptions influence the construction of the border concept of students in classrooms. Open-ended questionnaires answered by five Geography teachers from the institutions participating in the research were used to develop this paper. The teachers represented a border in drawing, they answered what they feel for the drawing and the meaning of their representation. However, teachers drew a border as the limit between two distinct realities, adding meanings of their daily lives.
\end{abstract}

Keywords: Border; Drawings; Geography teachers; Geography teaching; Perception.

\title{
1. Introdução
}

O desenho é uma linguagem não-verbal utilizada desde a antiguidade para representar as manifestações e fenômenos que ocorriam no espaço geográfico. Tornou-se inclusive percussor de outros tipos de artes e linguagens como a escrita, fotografia, pintura, cinema, charges, tiras humorísticas, histórias em quadrinhos e produtos cartográficos.

Os sujeitos quando desenham expressam uma visão e raciocínio particular que resulta dos processos físicos e mentais do indivíduo. Santos (2013) afirma que os elementos que são representados no desenho estão relacionados à cultura de cada sujeito, permeados pelo jogo da imaginação e o contexto social que estão inseridos.

O trabalho objetiva compreender e discutir como os professores de Geografia de três estabelecimentos públicos de ensino do Município de Marechal Cândido Rondon/PR, localizado geograficamente na fronteira internacional entre Brasil e Paraguai, representam o 
conceito de fronteira ${ }^{5}$ em desenho. No desenho da fronteira, além do conceito concreto, que consiste na explicação sobre o que é fronteira, estão presentes traços do espaço vivido e percebido pelos professores de Geografia.

Conforme Michenco (2011, p.16-17), trabalhar com o desenho da fronteira com os professores permite dar existência e possibilidade diante das “[...] percepções da realidade e à aproximação das ideias, imagens e conceitos que já permeiam [...] em seus pensamentos acerca da fronteira Brasil-Paraguai e do conceito de fronteira, presente nos currículos escolares, nos dizeres da imprensa, na construção cotidiana”. Quando os professores na/da fronteira representam a fronteira em desenho, expressam também a maneira como sentem e se relacionam de forma particular com esse espaço fronteiriço onde vivem.

O trabalho apresenta os resultados parciais do projeto de Iniciação Científica Voluntária intitulado: A percepção da fronteira dos docentes e discentes em colégios públicos de Marechal Cândido Rondon - PR (2016/2017), vinculado ao Laboratório de Ensino de Geografia (LEG) e Linha/Grupo de Pesquisa Ensino e Práticas de Geografia (ENGEO).

Justifica-se a pesquisa pelo papel que o professor de Geografia possui em possibilitar novas leituras de mundo aos alunos e a compreensão do espaço onde estão inseridos. Supõese que essas concepções de fronteira dos professores influenciam na forma como os alunos fronteiriços compreendem o conceito em questão. A construção conceitual de fronteira se dá nas aulas de Geografia pelas interferências internas do espaço escolar (livro didático e o posicionamento conceitual do professor) e das interferências externas (a mídia e as vivências pessoais dos estudantes).

O trabalho parte das reflexões de Michenco (2011) e Vanderlinde (2015) sobre a maneira como os sujeitos percebem a dinâmica do arranjo espacial em que estão inseridos: a fronteira internacional entre Brasil e Paraguai. Para a realização da pesquisa, entrevistou-se, no ano letivo de 2017, os professores de Geografia de três estabelecimentos de ensino de Marechal Cândido Rondon: Colégio Estadual Antônio Maximiliano Ceretta - Ensino Fundamental, Médio e Profissional, Colégio Estadual do Campo Nilso Franceski - Ensino Fundamental e Médio e Escola Estadual do Campo Porto Mendes - Ensino Fundamental. Participaram da pesquisa cinco professores, os quais, após a entrevista, receberam um questionário aberto. Nele deveriam desenhar sua concepção de fronteira, explicar nas questões posteriores o que representaram e sentiram desenhando. A partir desses retornos, buscou-se

\footnotetext{
${ }^{5}$ Entende-se a fronteira como o encontro e desencontro de duas ou mais realidades distintas, na perspectiva de Martins (2009), Michenco (2012) e Vanderlinde (2015).
} 
refletir sobre o modo que esses professores compreendem o conceito de fronteira e o representam no desenho.

O artigo está dividido em três momentos. Primeiro, discute-se o desenho como representação do espaço geográfico e suas contribuições para compreender o entendimento de fronteira dos professores de Geografia. No segundo momento, analisa-se a forma como os docentes representam o conceito de fronteira no desenho. Na conclusão, reflete-se sobre os resultados do trabalho e possibilidades de trabalhar o conceito de fronteira em sala de aula.

\section{Entre riscos e rabiscos e a construção conceitual da fronteira através do desenho}

O desenho é uma linguagem visual que acompanha a humanidade desde o começo da sua história. Na pré-história, os "homens das cavernas" utilizavam as pinturas rupestres grafadas nas superfícies rochosas de seus abrigos para expressar e registrar suas vivências no espaço geográfico. Esses desenhos serviam como forma de comunicação antes da consolidação da linguagem verbal e facilitava a comunicação entre os diferentes povos da região e membros das comunidades.

O desenho tem importância no cenário global, uma vez que se encontra presente em campanhas de publicidades, design dos produtos, muros, videoclipes, pinturas, entre outras formas. Na educação, ele tem papel fundamental, pois auxilia no desenvolvimento da criatividade, da liberdade de pensar e pode expressar a forma que os estudantes compreendem o mundo e o espaço onde estão inseridos. Ao desenhar, estimula-se o hemisfério direito do cérebro, responsável pela imaginação, criatividade, serenidade, visão global, facilidade de memorização e outras habilidades emocionais. (ANDRADE et al., 2007).

Os riscos e rabiscos que formam os desenhos expressam sentimentos e emoções que os sujeitos esboçam no papel. Santos (2013) explana que esses desenhos são espontâneos e copiativos, ou seja, eles são naturais, ilustram os anseios de quem desenha e ao mesmo tempo são imitativos, partem dos aspectos visíveis dos pensamentos e das memórias. Os desenhos são construídos de dentro para fora através do processo de desenvolvimento geral do conhecimento. Eles revelam a natureza do pensamento do sujeito que é resultado das experiências vividas no espaço geográfico.

Para Oliveira Junior (2014), o ato de desenhar não está vinculado com regras explícitas entre o desenho e a realidade igual às representações cartográficas, mas sim através da cultura e concepção de cada desenhista de maneira subjetiva e particular.

Entende-se que 
os desenhos não são fixos, envolvem momentos de percepção que são construídos sucessivamente (pela ação), para resultar numa expressão gráfica. A compreensão da natureza dessa ação envolve a percepção e a representação gráfica, numa tentativa de traduzir este ato. Devemos nos esforçar mais para entender essa "tradução", pois é desse ato que surgirá o desenho. (SANTOS, 2013, p.196).

Almeida (2001) alega que os desenhos não são cópias, mas interpretações pessoais da realidade que partem de um sistema de representação. Os desenhos revelam o modo particular que os sujeitos pensam o espaço. Dessa forma, "trabalhar com os desenhos é trabalhar com novas formas de ver, compreender as 'coisas' e verificar-comprovar as próprias ideias. O indivíduo, quando desenha, expressa uma visão e um raciocínio.” (SANTOS, 2013, p.195).

Ao desenhar o que entende por fronteira, o professor expressa no papel, além do conceito de fronteira, as percepções que desenvolveu ao longo da vida e formação acadêmica. Essa concepção influenciará significativamente na formação do conceito de fronteira dos alunos, pois "a ação pedagógica desses professores é [...] de certa maneira interventiva, para contribuir e favorecer no processo de ensino-aprendizagem, conduzindo os alunos a um melhor entendimento do mundo que o[sic] cerca." (MICHENCO, 2011, p.119).

\subsection{Percepções sobre as fronteiras dos professores representadas nos desenhos}

A Geografia da percepção está relacionada “em seus procedimentos metodológicos de investigações sobre a maneira como as pessoas sentem o espaço em que vivem e como se relacionam com ele." (KOZEL; FILIZOLA, 1996, p.15). Por meio dos desenhos dos professores, buscou-se interpretar o modo como eles compreendem o conceito de fronteira e o constroem em sala de aula.

Através dos retornos dos professores, percebeu-se um estranhamento e resistência perante o solicitado com a pesquisa. Quando procurados por pesquisadores respondiam somente questionários ou eram entrevistados. A pesquisa em questão solicitou a representação dos seus conhecimentos em desenho. O desenho é uma prática tradicionalmente utilizada por eles em sala de aula com fins pedagógicos, porém, na pesquisa, eles foram desafiados a desenhar o que definem por fronteira. Houve uma inversão dos papeis: os professores assumiram os lugares tradicionalmente ocupados pelos alunos.

Para Pontuschka, Paganelli e Cacete (2009), os desenhos são espontâneos e possibilitam compreender o desenvolvimento gráfico-espacial de quem desenha, ilustram não somente as informações sobre os lugares, mas também o imaginário sociocultural. Os desenhos oferecem dados sobre situações de vida, pensamentos e medos dos sujeitos. 
O desenho exigiu dos professores reflexão diferenciada. Eles tiveram que pensar como a fronteira é discutida na literatura e imaginar como poderiam caracterizá-la no desenho. Além de formularem um conceito de fronteira, tiveram que expressar no desenho suas visões e ideias acerca do conceito que também corresponde ao espaço vivido: a fronteira internacional entre Brasil e Paraguai.

Para Vanderlinde (2015), a fronteira é um conceito com vários sentidos, construído pelos sujeitos através do imaginário e das próprias experiências. Dessa forma, ela

[...] é aquilo que cada um representa, criada por aquele que a transpõe diariamente, esporadicamente ou nunca. Refletir na, e sobre a fronteira, é levar em conta um espaço privilegiado da produção de antagonismos, mas também de laços de solidariedade, da afirmação e negação de identidades, da (re)elaboração de representações, da (re)invenção de lendas e tradições, do (des)encontro dos homens, dos conflitos e das conquistas materiais (VANDERLINDE, 2015, p.6).

Portanto, o indivíduo representa a fronteira de acordo com suas vivencias e as relações que estabelece com ela. Cardin (2014) problematiza o cotidiano do espaço fronteiriço, afirmando que o ato de viver na fronteira, muitas vezes, ocorre de maneira despercebida aos olhos da população fronteiriça, que estabelece relação particular com a fronteira, diferente do sujeito que vive distante dela e guarda no imaginário o simbolismo de transpor um limite internacional, o habitante fronteiriço acaba naturalizando essas especificidades:

\begin{abstract}
Existem múltiplas formas de viver na fronteira, a grande maioria delas ocorre de maneira despercebida pelos próprios moradores das regiões limítrofes. Habituados a cruzar as pontes, os rios e as ruas que separam os diferentes países vizinhos do território brasileiro, a população fronteiriça possui uma relação muito particular com a situação no qual se encontra. Diferente dos visitantes e turistas que pensam e guardam no imaginário o simbolismo de estarem em uma nação diferente da sua, os moradores locais, das 'raias' brasileiras têm tais sensações mais naturalizadas, inserindo as possibilidades fronteiriças cotidianamente em suas experiências e, consequentemente, na organização das estratégias necessárias para o desenvolvimento de suas práticas sociais (CARDIN, 2014, p.43).
\end{abstract}

Os professores de Geografia, ao desenharem o que entendem e assemelham por fronteira, representaram o conceito como um limite entre realidades distintas, como um espaço privilegiado da produção de antagonismos, cada um com uma característica diferente, levando em consideração as próprias percepções. Oliveira Junior (2010) complementa afirmando que no desenho podem-se observar as principais aproximações e preocupações que os professores têm ao trabalhar os conteúdos.

No primeiro desenho (Figura 1), o professor I representa a fronteira como limite físico natural entre dois ou mais lugares distintos, que em muitos casos são utilizados como limites 
internacionais; por exemplo, o caso do Estado do Paraná, onde o lago de Itaipu separa Brasil e Paraguai.

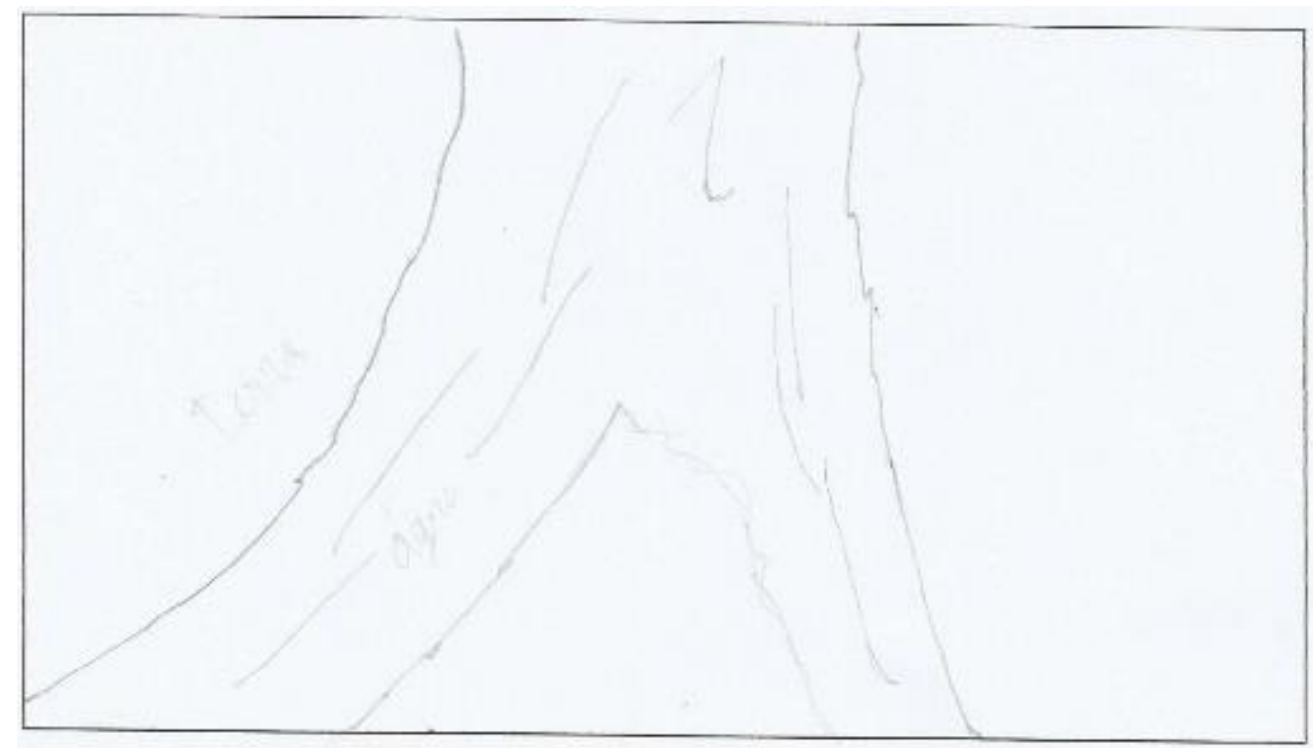

Figura 1 - Desenho sobre as percepções da fronteira do professor I. Fonte: Professor I.

No entanto, o professor I discorda do conceito de fronteira, no sentido de separação, divisão ou compartimentação, acredita que não existem limites para os homens, que transpõem cotidianamente os limites internacionais entre os países; não os visualiza até mesmo na localidade onde trabalha, a escola recebe contingente significativo de alunos oriundos do Paraguai, decorrente de sua localização próxima à linha imaginária da fronteira e as condições educacionais do país. O professor não admite a existência de fronteira entre Estados nacionais, mas enxerga diferente: percebe outras fronteiras na sociedade. Segundo ele, "não há fronteiras para os homens, há fronteiras para a ignorância e preconceito".

Portanto, supõe-se que o professor provoca quem vê o desenho e ouve sua fala, parte de outras perspectivas para trabalhar o conceito fronteira. Assim, arrisca-se pensar que o professor, por estar inserido num estabelecimento com alunos oriundos de outro país que se encontram no mesmo ambiente escolar sem barreiras ou separações, não valoriza o debate sobre fronteiras.

Referente à experiência de realizar o desenho sobre a fronteira, o professor I afirma que "vivemos num planeta que pode ser destruído a qualquer momento, por vários fatores, um asteroide por exemplo, e nos preocupamos com coisas banais". Nas palavras do professor, seu posicionamento é contrário às discussões oficiais e acadêmicas em torno do conceito de 
fronteira. $\mathrm{Na}$ visão do respondente, existem assuntos mais graves para se preocupar e pesquisar que a forma como os professores e alunos compreendem o conceito de fronteira.

Ao mesmo tempo em que o professor desconsidera a existência de fronteiras entre dois países, pressupõe-se que, em sua prática docente, ao interagir com estudantes oriundos de outros países, como acontece em sua escola, e não os diferir, pode causar e estimular a invisibilidade da cultura e identidade desses estudantes.

No segundo desenho (Figura 2), o contrário acontece com o professor IV, que representa a fronteira como limite internacional, a divisão entre dois países:

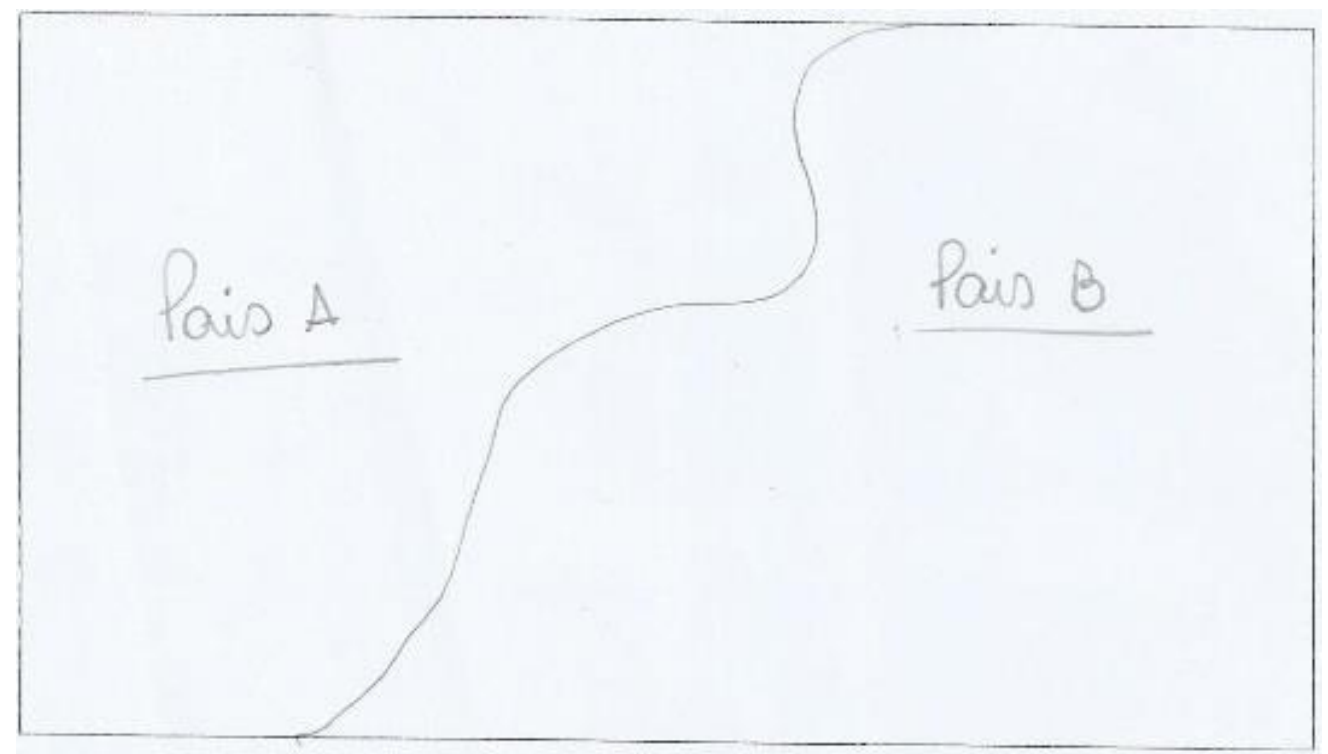

Figura 2 - Desenho sobre as percepções da fronteira do professor IV. Fonte: Professor IV.

O professor IV retrata em seu desenho a fronteira política-territorial entre Estados nacionais que "[...] partem da invenção do homem para representar, organizar, controlar ou dominar determinado espaço territorial.” (FERRARI, 2014, p.46). O professor justifica afirmando que "[...] o desenho representa o conceito de fronteira partindo de uma separação, divisão, compartimentação. É apenas uma linha divisória entre dois países distintos”.

A concepção de fronteira empregada no desenho pelo professor IV é a noção de limite internacional que representa a linha de fronteira. "O limite é abstrato e invisível, fruto de um tratado jurídico internacional ou delimitação.” (ALBUQUERQUE, 2010, p.35). Essa noção de limite é frequentemente confundida com a fronteira, porém esta se configura no território “[...] como uma zona, uma faixa ou região entre dois países, é um espaço mais amplo de relações sociais de um lado e outro do limite político.” (ALBUQUERQUE, 2010, p.35). 
Ao descrever o que sentiu ao desenhar a fronteira, o professor IV afirma ter sido "muito difícil representar um tema tão complexo com um desenho, espero que ele tenha sido autoexplicativo". A fronteira pode ser empregada em vários sentidos que vão além do aspecto territorial. Eles podem ser físicos (dois territórios separados por um rio), culturais (conflitos entre latifundiários e indígenas) ou até metafóricos (fronteira entre professores e alunos). As fronteiras podem ser modificadas e até extintas com o tempo, por isso torna-se difícil representá-las em desenho.

Fica visível que o ato de representar a fronteira em desenho exige mais que conceituar em palavras. Além do conhecimento científico, no desenho é expressa a visão que os sujeitos possuem do espaço geográfico, formada empiricamente através das próprias vivências. Frasson e Schlosser (2014, p.78) alertam que essas concepções de fronteira dos professores “[...] podem mostrar ou ocultar elementos necessários à compreensão do espaço geográfíco em seus limites e possibilidades". No terceiro desenho (Figura 3) do professor III, podem-se observar algumas impressões sobre o espaço geográfico que foram adquiridas ao longo da vida pelo docente:

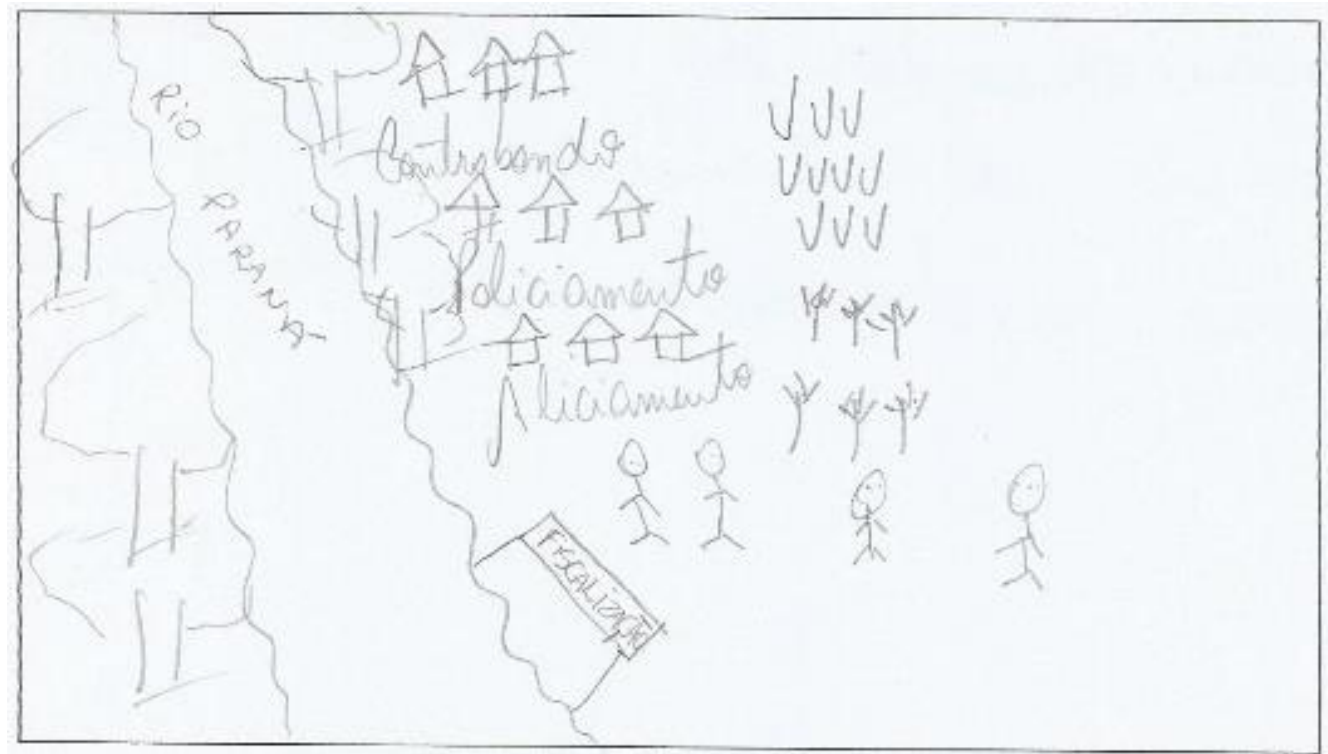

Figura 3 - Desenho sobre as percepções da fronteira do professor III. Fonte: Professor III.

O professor III representa a fronteira internacional entre Brasil e Paraguai vivenciada em seu cotidiano. Agrega ao desenho aspectos particulares dessa região fronteiriça, como aliciamento, policiamento e contrabando, que são noticiadas pela mídia e compõem a imagem que muitos habitantes não fronteiriços têm da fronteira e o rio Paraná que separa e, ao mesmo tempo, une esses dois territórios e torna-se palco desses acontecimentos. 
Justifica ao dizer que:

A fronteira representada é a da minha vivência. Percebi que tenho uma visão que evidencia os problemas que envolvem as fronteiras, como tráfico, policiamento, fiscalização desta região. Mas, por outro lado, neste espaço de fronteira a vida decorre de maneira normal ou igual a qualquer outro lugar em relação as[sic] necessidades básicas de educação, saúde, trabalho etc, no entanto, ao que se refere $\mathrm{a}$ [sic] circulação de pessoas oriundas de diferentes lugares, tráfico e criminalidade, esta região se diferencia das demais.

O professor III relata que, no espaço de fronteira, a população possui as mesmas necessidades que as pessoas das demais regiões do país, porém convive com particularidades que caracterizam a fronteira como um espaço perigoso, práticas como tráfico, criminalidade, contrabando e a circulação de pessoas de outros países. Um aspecto que fica evidenciado no desenho é o aliciamento dos responsáveis pela segurança dessa região, marcado pela placa de fiscalização caída na representação. Ao desenhar suas percepções acerca da fronteira, afirma que teve "a sensação que levou a refletir sobre o tema e sobre minha própria concepção de fronteira".

O quarto desenho (Figura 4) retrata o encontro e desencontro de realidades opostas. A fronteira é caracterizada no sentido figurado, noção usualmente utilizada no vocabulário cotidiano das pessoas que vai além do conceito geográfico, representada pelo professor II:

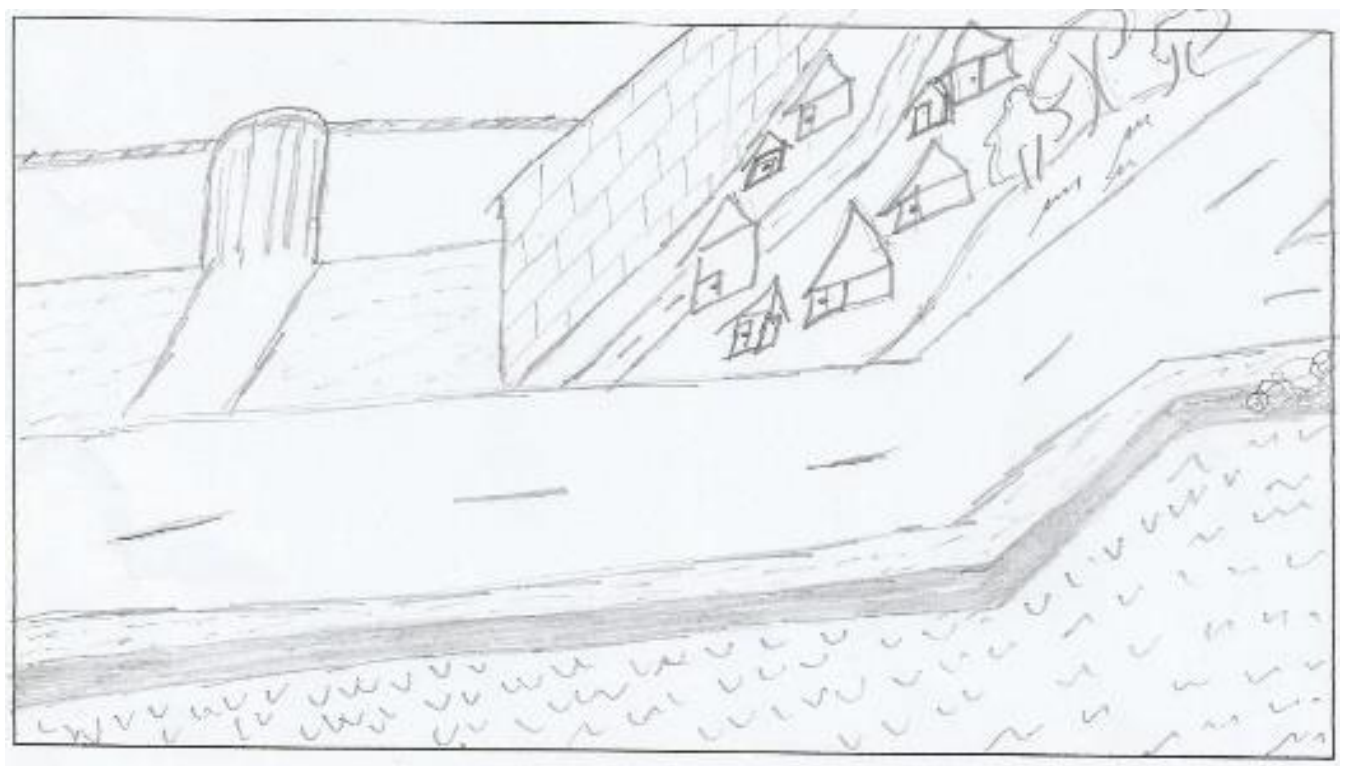

Figura 4 - Desenho sobre as percepções da fronteira do professor II.

Fonte: Professor II.

O professor II explica a fronteira de forma metafórica, indo além do sentido convencional de limite internacional entre dois ou mais países. Justifica ao dizer que procurou 
“[...] representar a fronteira física (da bicicleta e do carro), a fronteira econômica (das construções maiores e menores), da fronteira visível do muro e a invisível das oportunidades sociais". Esse modo de perceber a fronteira "em geral dar-se-á de forma difusa, seus limites constituídos em sutis barreiras sociais e culturais, mas nem por isso, menos impositivas." (CASTROGIOVANNI; GASTAL, 2006, p.6). O desenho retrata fronteiras presentes nos espaços da sociedade, o conflito gerado pelo (des)encontro de realidades sociais e culturais distintas presente no cotidiano.

Ao expressar o que sentiu ao desenhar a fronteira, o professor II declara que a experiência foi "um tanto estranha, no momento que falamos parecia fácil. O desenhar se torna algo abstrato para quem vê, e a interpretação pode não ser a mesma de quem desenhou". Ao visualizar o desenho sem um olhar crítico, pode-se imaginar que ele não retrata a fronteira. O desenho vai além do sentido das fronteiras internacionais: o professor expõe as fronteiras sociais e culturais que são erguidas diariamente na sociedade capitalista.

No quinto desenho (Figura 5), o professor $\mathrm{V}$ representa a fronteira como a faixa de transição entre diferentes territórios. Segundo o professor,

a intenção do desenho é de representar o limite entre os dois países vizinhos, definido pelo rio. Um limite concreto e demonstrar que o limite demarca a fronteira entre os países. Porém a fronteira também pode ser definida como uma faixa de terra entre os dois países. Uma área de transição.

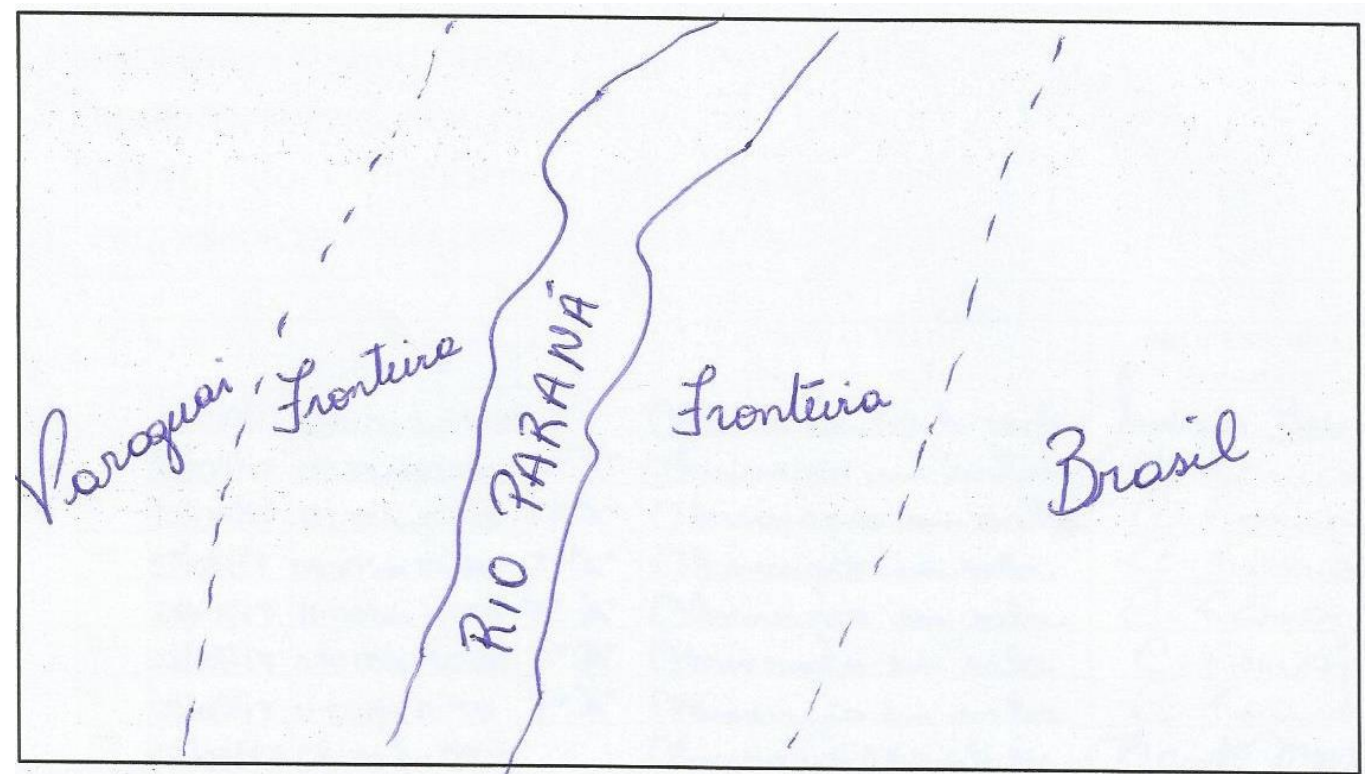

Figura 5 - Desenho sobre as percepções da fronteira do professor V.

Fonte: Professor V.

Essa concepção também é encontrada nos livros didáticos, que conceituam a fronteira como "[...] uma faixa do território de um país que se estende ao longo da linha de limite." 
(BOLIGIAN et al., 2012, p.14). No território brasileiro, a faixa de fronteira corresponde aos $150 \mathrm{~km}$ de largura, paralelos à linha divisória território nacional, estabelecida pela Lei $\mathrm{n}^{\circ}$ 6.634/79 e regulamentada pelo Decreto ${ }^{\circ} 85.064$ de 26 de agosto de 1980.

$\mathrm{O}$ professor $\mathrm{V}$ relata no questionário que, ao representar a fronteira em desenho, buscou “[...] na representação do desenho concretizar o conceito de fronteira. Visualizá-lo". Explica que organizou seu desenho sobre a fronteira a partir do limite internacional que demarca a fronteira e dá possibilidades para as populações fronteiriças elaborarem suas práticas e estratégias de vida entre os dois países.

Em síntese, o desenho possui potencial de ensinar e construir através dos riscos e rabiscos o conhecimento. Expressa e transforma uma ideia em algo visível para o mundo. Permite mais interpretações do que a descrição efetuada pela escrita ou fala. Representar a fronteira em desenho mostra outras formas de pensar esse espaço de confronto e proximidade entre realidades opostas. Ademais, revela a natureza do pensamento de cada professor, formado através do processo de desenvolvimento geral do conhecimento por meio de sua formação acadêmica e de suas vivências pessoais.

\section{Conclusões}

Ao representar em forma de desenho a fronteira, os professores fogem da prática habitual e técnica da escrita e das palavras. Expressam através dos riscos e rabiscos de maneira pessoal e particular suas percepções sobre a fronteira. Através dos retornos, pode-se verificar que a fronteira é um conceito que abrange vários sentidos e significados.

A fronteira aparece nos desenhos como: um limite físico natural; uma linha imaginária que separa dois ou mais países; a fronteira como um espaço de contrabando e contravenção; fronteiras sociais e culturais criadas pelas desigualdades e diferenças na sociedade; fronteira econômica; fronteira das oportunidades; fronteira como uma faixa de transição entre os Estados nacionais.

A pesquisa fez os professores refletirem sobre o conceito, que por vezes ficava despercebido no livro didático. Estavam acostumados com o cotidiano fronteiriço e não paravam para pensar sobre suas implicações. Eles puderam refletir sobre a complexidade da fronteira e sobre o espaço no qual estão inseridos, agregando-lhes não apenas conhecimento científico, mas também de suas vivências pessoais no desenho.

Fica evidente que a construção das diferentes concepções e relações com a fronteira ocorre de acordo com o modo de vida das pessoas e sua proximidade com o diferente. Nesse 
sentido, pretende-se aqui apontar algumas sugestões que podem auxiliar o trabalho do professor na construção desse conceito em sala de aula.

Faz-se necessário estabelecer a diferença entre fronteira, limite e divisa. Conceitos que foram tratados como sinônimos nas respostas dos professores. Fronteira não é apenas uma linha imaginária que divide uma nação de outra, trata-se de algo mais amplo e dinâmico, portanto, ultrapassa o sentido de limite internacional, visto que diariamente ocorre a criação e imposição de novas fronteiras sociais e culturais na sociedade.

Essas fronteiras são tensionadas pela própria ação humana (manifestações religiosas, determinados hábitos culturais, situações socioeconômicas desiguais, etc.), que são modificadas e possuem um "prazo de validade" menor, mas interferem na sociedade. O limite é um conceito estático que sinaliza uma demarcação. Trata-se de uma linha imaginária e abstrata que separa dois territórios (municípios, estados ou países). Logo, refere-se a uma delimitação de área construída por acordos e tratados. A divisa é o aspecto físico e visível desse limite, que pode ser natural ou antrópico (rio, montanha ou um marco construído pela ação humana).

Nesse sentido, a fronteira pode ser considerada uma faixa de terra que se estende no limite entre dois territórios, contudo, marcada por intenso intercâmbio e trocas econômicas, sociais e culturais. Ela se refere ao encontro do diferente; está vinculada com realidades distintas. Dessa forma, ganha outros sentidos, como: fronteira do amor proibido ou não correspondido; fronteira entre ricos e pobres; fronteiras de duas culturas diferentes; fronteira entre professores e alunos ou professores e coordenação pedagógica; entre outras fronteiras formadas e impostas na sociedade.

Diante do exposto, compreende-se que, para os habitantes da fronteira internacional de dois ou mais países, este conceito é peculiar, próprio dos sujeitos desta localidade. A fronteira expressa união e oportunidades de acesso à saúde, educação e trabalho de um lado e de outro, manifestado de formas distintas de acordo com as necessidades locais. Entretanto, para o sujeito que não vive na fronteira (ou um pouco distante dela), frequentemente ela é vista como sinônimo de periculosidade, ligado a práticas de contrabando, crime organizado, marginalidade e narcotráfico, que são discursos vinculados pela mídia.

Espera-se que as discussões desta pesquisa contribuam com a prática educativa do professor de Geografia, de modo que o mesmo tenha a preocupação de fazer as aproximações necessárias do conceito de fronteira com o espaço vivido dos próprios alunos e deles mesmos.

O intuito do trabalho foi refletir a partir das percepções dos professores de Geografia sobre a fronteira, a importância dos alunos fronteiriços se reconhecerem como habitantes 
na/da fronteira, com particularidades que interferem diretamente no ordenamento socioespacial da dinâmica onde vivem, portanto, que influenciam na formação da consciência geográfica a partir do espaço vivido e a prática da cidadania.

\section{Referências}

ALBUQUERQUE, J. L. C. A dinâmica das fronteiras: Os brasiguaios na fronteira entre o Brasil e o Paraguai. São Paulo: Annablume, 2010. 266 p.

ALMEIDA, R. D. Do desenho ao mapa: iniciação cartográfica na escola. São Paulo: Contexto, 2001. 115 p.

ANDRADE, A. F. et al. A Contribuição do Desenho de Observação no Processo de EnsinoAprendizagem. In: XVIII Simpósio Nacional de Geometria e Desenho Técnico e VII International Conference on Graphics Engineering for Arts and Design, 2007, Curitiba. Anais... Curitiba, 2007.

BOLIGIAN, L. et al. Geografia - Espaço e vivência: A organização do espaço brasileiro ( $7^{\circ}$ ano). 4. ed. São Paulo: Saraiva, 2012. 180 p.

CARDIN, E. G. Teoria das fronteiras e totalidade. In: COLOGNESE, S. A.; CARDIN, E. G. (Orgs.). As ciências sociais na fronteira: teorias e metodologias de pesquisa. Cascavel: JB, 2014. p. 43-59.

CASTROGIOVANNI, A. C.; GASTAL, S. Fronteiras e turismo: tencionando conceitos. In: IV SEMINTUR - Seminário de Pesquisa em Turismo do Mercosul, 2006, Caxias do Sul, Anais... Caxias do Sul, 2006.

FERRARI, M. As Noções de Fronteira em Geografia. Perspectiva Geográfica, v. 09, n. 02, p. 45-64, 2014. ISSN: 1981-4801. Disponível em: <http://erevista.unioeste.br/index.php/pgeografica/article/view/10161/7550>. Acesso em: 23 abr. 2017.

FRASSON, M.; SCHLOSSER, M. T. S. Concepções e percepções de fronteiras dos Professores da Educação Básica revelada por meio da foto-resposta (Extremo Oeste do Paraná - 2012). Geografia Ensino \& Pesquisa, v. 18, p. 77-96, 2014. ISSN 2236-4994. Disponível em: 〈https://periodicos.ufsm.br/geografia/article/view/11337>. Acesso em: 15 mai. 2017.

KOZEL, S.; FILIZOLA, R. Didática de geografia - memórias da Terra: o espaço vivido. São Paulo: FTD, 1996. 112 p.

MARTINS, J. S. Fronteira: a degradação do outro nos confins do humano. 2. ed. São Paulo: Contexto, 2009. 213 p.

MICHENCO, S. M. Representações da fronteira Brasil-Paraguai segundo alunos do $3^{\circ}$ ano do ensino médio em Amambai-MS. 2011. 124 f. Dissertação (Mestrado em Geografia) Universidade Federal da Grande Dourados, Dourados, MS. 2011. 
OLIVEIRA JUNIOR, W. M. Desenhos e escultas. In: NUNES, F. G. (Org.). Ensino de geografia: novos olhares e práticas. Dourados: Editora da Universidade Federal da Grande Dourados, 2011. p. 13-36.

PONTUSCHKA, N. N.; TOMOKO, I. P.; CACETE, N. H. Para ensinar e aprender Geografia. 3. ed. São Paulo: Cortez, 2009. 383 p.

SANTOS, C. O uso dos desenhos no ensino fundamental: imagens e conceitos. In: PONTUSCHKA, N. N.; OLIVEIRA, A. U. (Orgs.). Geografia em Perspectiva: ensino e pesquisa. São Paulo: Contexto, 2013. p. 195-207.

VANDERLINDE, T. Transformações fronteiriças no Oeste do Paraná. In: III Seminário Internacional de los Espacios de Frontera, 2015, Encarnacion. Anais... Encarnacion, 2015. 